\title{
The Methyl Torsion in Unsaturated Compounds
}

\author{
Andrea Zachariou, Alexander P. Hawkins, Paul Collier, Russell F. Howe, David Lennon, \\ and Stewart F. Parker*
}

Cite This: ACS Omega 2020, 5, 2755-2765

Read Online

\section{ACCESS | Lلll Metrics \& More | 四 Article Recommendations | SI Supporting Information}

ABSTRACT: How the methyl torsion transition energy in unsaturated systems is affected by its environment is investigated. It is strongly influenced by both its immediate neighborhood, (the number of methyl groups present in the molecule) and the intermolecular interactions. It is clear that the intermolecular interactions have a major influence on the torsion transition energy, as demonstrated unambiguously previously for mesitylene

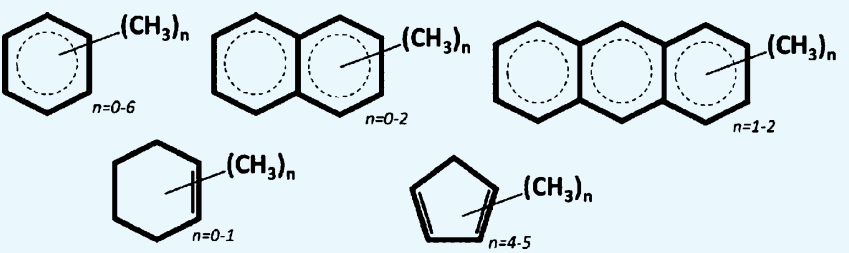
and also seen here for other systems. In part, this may be caused by the fact that the methyl torsion is rarely a pure mode (unless enforced by symmetry). Where the crystal structure is available, the assignments have been supported by CASTEP calculations of the unit cell. The agreement between the observed and calculated spectra is generally good, although not perfect, toluene being a case in point, and highlights just how demanding it is to obtain accurate transition energies for low energy modes. The disagreement between observed and calculated inelastic neutron scattering spectra for meta-xylene and 9,10 dimethylanthracene is so severe that it would suggest that there are additional phases to those presently known. Comparison between the full periodic calculations and those for the isolated molecule shows that intermolecular interactions raise the methyl torsion transition energy by at least $8 \%$ and in some cases by more than $50 \%$. The presence of more than one methyl group in the molecule generally raises the average torsion energy from the $<100 \mathrm{~cm}^{-1}$ seen for single methyl groups to $150-200 \mathrm{~cm}^{-1}$.

\section{INTRODUCTION}

Methyl groups are ubiquitous in organic molecules. Consequently, their vibrational spectra have been studied since the early days of infrared spectroscopy. ${ }^{1}$ In a $\mathrm{CH}_{3}-\mathrm{X}(\mathrm{X}=$ nonlinear polyatomic moiety) system, there will be nine modes associated with the three hydrogen atoms of the methyl group: three $\mathrm{C}-\mathrm{H}$ stretches at $\sim 3000 \mathrm{~cm}^{-1}$, three $\mathrm{C}-\mathrm{H}$ bends at $\sim 1400 \mathrm{~cm}^{-1}$, two rocking modes at $700-1000 \mathrm{~cm}^{-1}$, and a torsion at low energy. With the exception of the torsion, all of these have been extensively investigated, resulting in the wellknown correlation tables. ${ }^{2-4}$

The methyl torsion has been much less studied. This arises because the vibration is at low energy, always $\leq 400 \mathrm{~cm}^{-1}$ and generally $\leq 250 \mathrm{~cm}^{-1}$; a region that is, historically, not readily accessible by infrared or Raman spectroscopy: thus conventional infrared spectrometers cutoff at $400 \mathrm{~cm}^{-1}$. The second reason is more fundamental, the vibration is often forbidden by optical, that is symmetry-based, selection rules or has very low intensity. The only technique that is readily able to observe the methyl torsion is inelastic neutron scattering (INS) spectroscopy, ${ }^{5}$ so much so that the methyl torsion is often the strongest band in the spectrum. This arises because of several reasons: neutrons are scattered by nuclei, not electrons, so there are no selection rules, the intensity is determined by the scattering cross section of the atom, of which ${ }^{1} \mathrm{H}$ has the largest magnitude and the amplitude of vibration, which is large for the methyl torsion. This has enabled comprehensive studies of the in-plane ${ }^{6,7}$ and out-of-plane ${ }^{8} \mathrm{C}-\mathrm{C}-\mathrm{C}$ bending modes of the $n$-alkanes (the longitudinal and transverse acoustic modes, LAM and TAM, respectively), the latter of which includes the methyl torsion. It is found at: $289 \mathrm{~cm}^{-1}$ for ethane, $233 / 277$ $\mathrm{cm}^{-1}$ for propane, $234 / 265 \mathrm{~cm}^{-1}$ for butane, $244 / 257 \mathrm{~cm}^{-1}$ for hexane, and $250 \pm 5 \mathrm{~cm}^{-1}$ for $n \geq 11$. $^{5,7,8}$ In the longer $n$ alkanes the coupling between the ends of the molecule is essentially zero and the in-phase and out-of-phase torsions are accidently degenerate, so only a single mode is seen.

In contrast to the $n$-alkanes, for other systems the effect of the environment on the transition energy of the methyl torsion has been much less explored. In this paper, we characterized the methyl torsion in a range of cyclic and polycyclic unsaturated compounds. In particular, we present the INS spectra of all 13 methylated benzenes: $\mathrm{C}_{6} \mathrm{H}_{6-x}\left(\mathrm{CH}_{3}\right)_{x}(x=0-$ $6)$.

\section{RESULTS AND DISCUSSION}

We have measured the INS spectra of all the possible methylated benzenes, some polycyclic aromatic compounds and some cyclic $\mathrm{C}_{5}$ and $\mathrm{C}_{6}$ alkenes. The spectra in the region below $600 \mathrm{~cm}^{-1}$, where the methyl torsions are expected, are

Received: October 9, 2019

Accepted: January 24, 2020

Published: February 7, 2020 

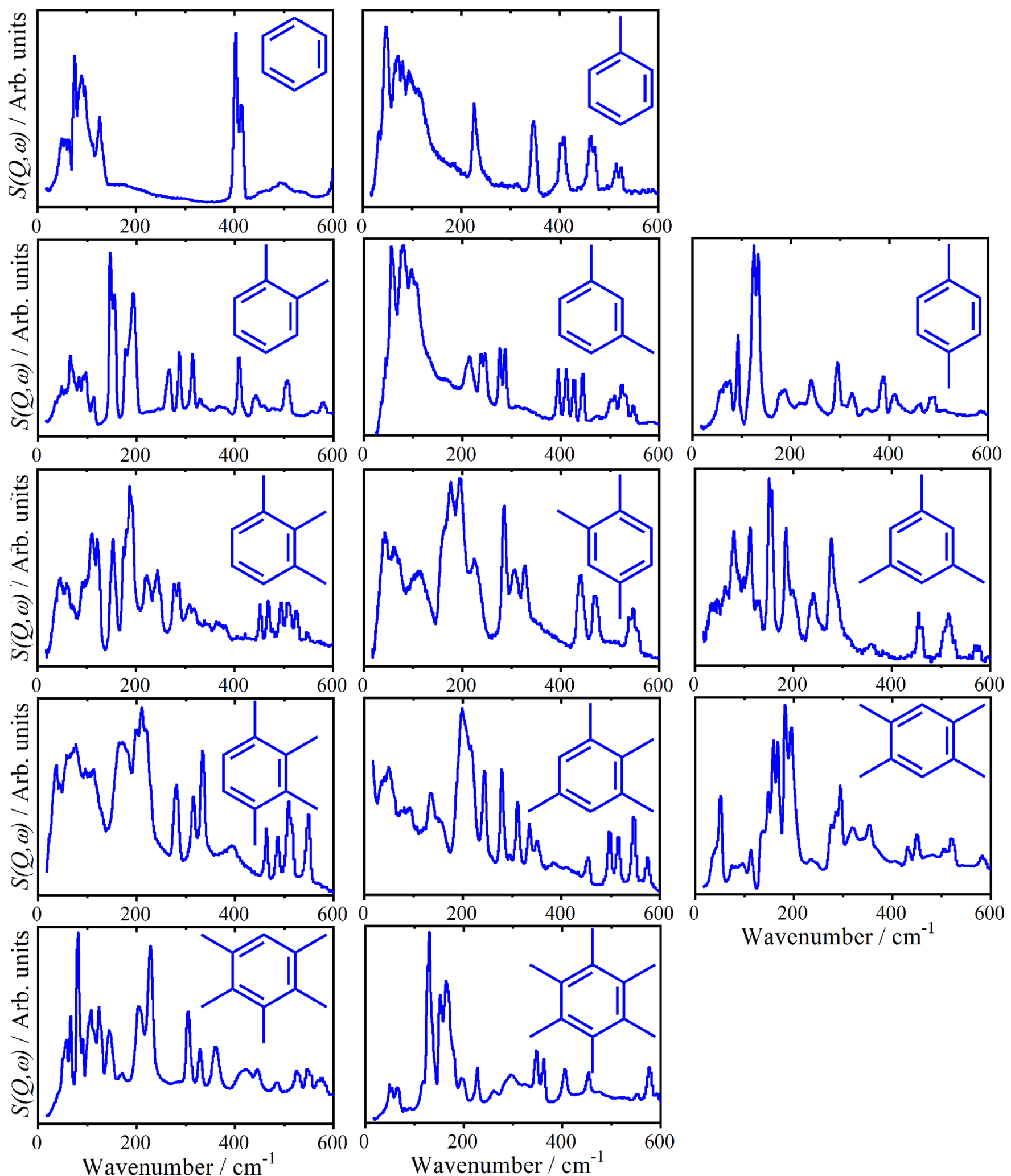

Figure 1. INS spectra at $<20 \mathrm{~K}$ of all the isomeric methylated benzenes, $\mathrm{C}_{6} \mathrm{H}_{6-x}\left(\mathrm{CH}_{3}\right)_{x}(x=0-6)$. Top row, left-to-right: benzene and toluene, second row, left-to-right: $o$-xylene, $m$-xylene, $p$-xylene, third row, left-to-right: 1,2,3-trimethylbenzene, 1,2,4-trimethylbenzene, 1,3,5trimethylbenzene, fourth row, left-to-right: 1,2,3,4-tetramethylbenzene, 1,2,3,5-tetramethylbenzene, 1,2,4,5-tetramethylbenzene, fifth row, left-toright: pentamethylbenzene and hexamethylbenzene.

shown in Figures $1-4$. The spectra for the $0-1800 \mathrm{~cm}^{-1}$ range are presented in the Supporting Information, Figures S1-S24.

The INS spectra of most compounds have been reported previously: benzene, ${ }^{9}$ toluene, ${ }^{10,11} \mathrm{~m}$ - and $p$-xylene, ${ }^{11,12}$ mesitylene, ${ }^{13}$ durene, ${ }^{14}$ pentamethylbenzene, ${ }^{15}$ and hexamethylbenzene, ${ }^{16}$ however, these are generally either (or both) of a much lower resolution and/or restricted energy transfer range than those reported here. 

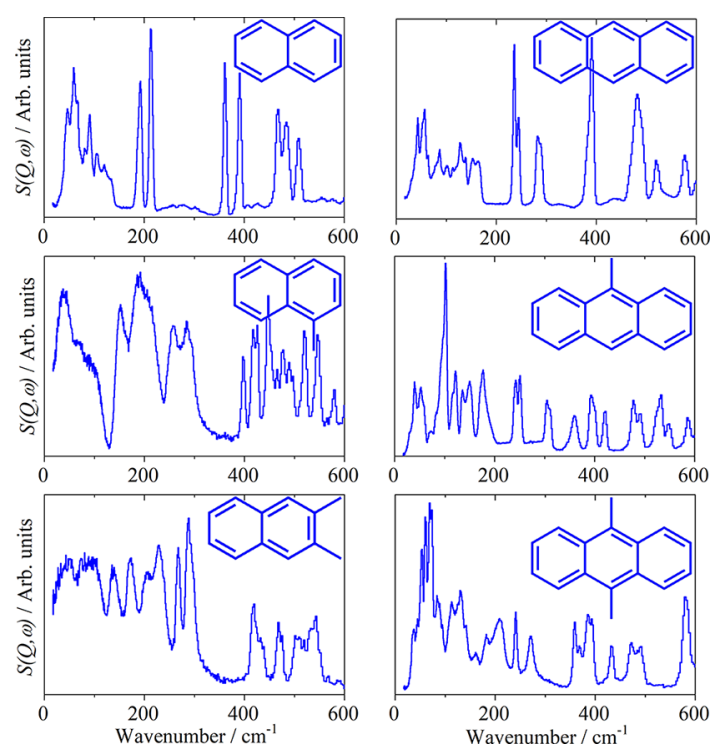

Figure 2. INS spectra at $<20 \mathrm{~K}$ of the parent and some methylated naphthalenes and anthracenes. Left side, top-to-bottom: naphthalene, 1-methylnaphthalene, and 2,3-dimethylnaphthalene. Right side, topto-bottom: anthracene, 9-methylanthracene, and 9,10-dimethylanthracene.
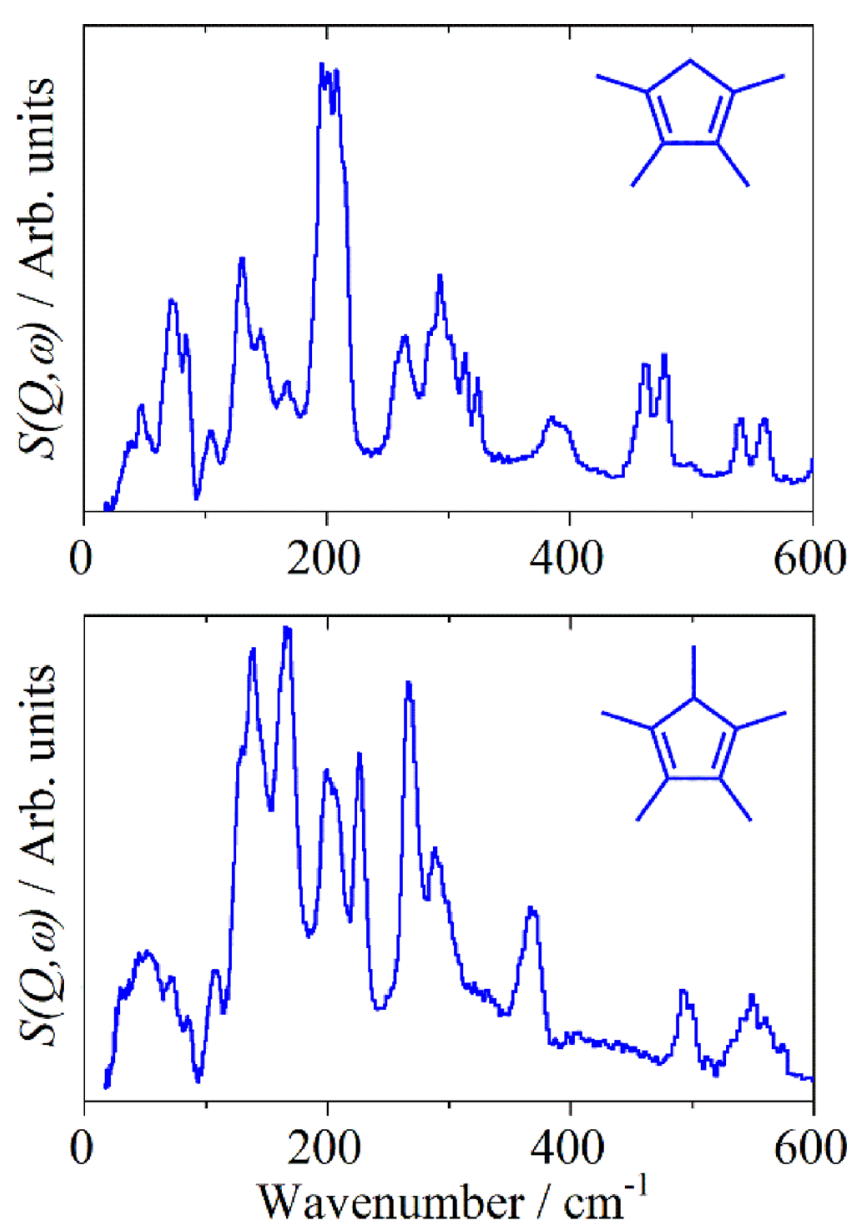

Figure 3. INS spectra at $<20 \mathrm{~K}$ of (top) 1,2,3,4-tetramethyl-1,3cyclopentadiene (85\%) and (bottom) 1,2,3,4,5-pentamethyl-1,3cyclopentadiene.
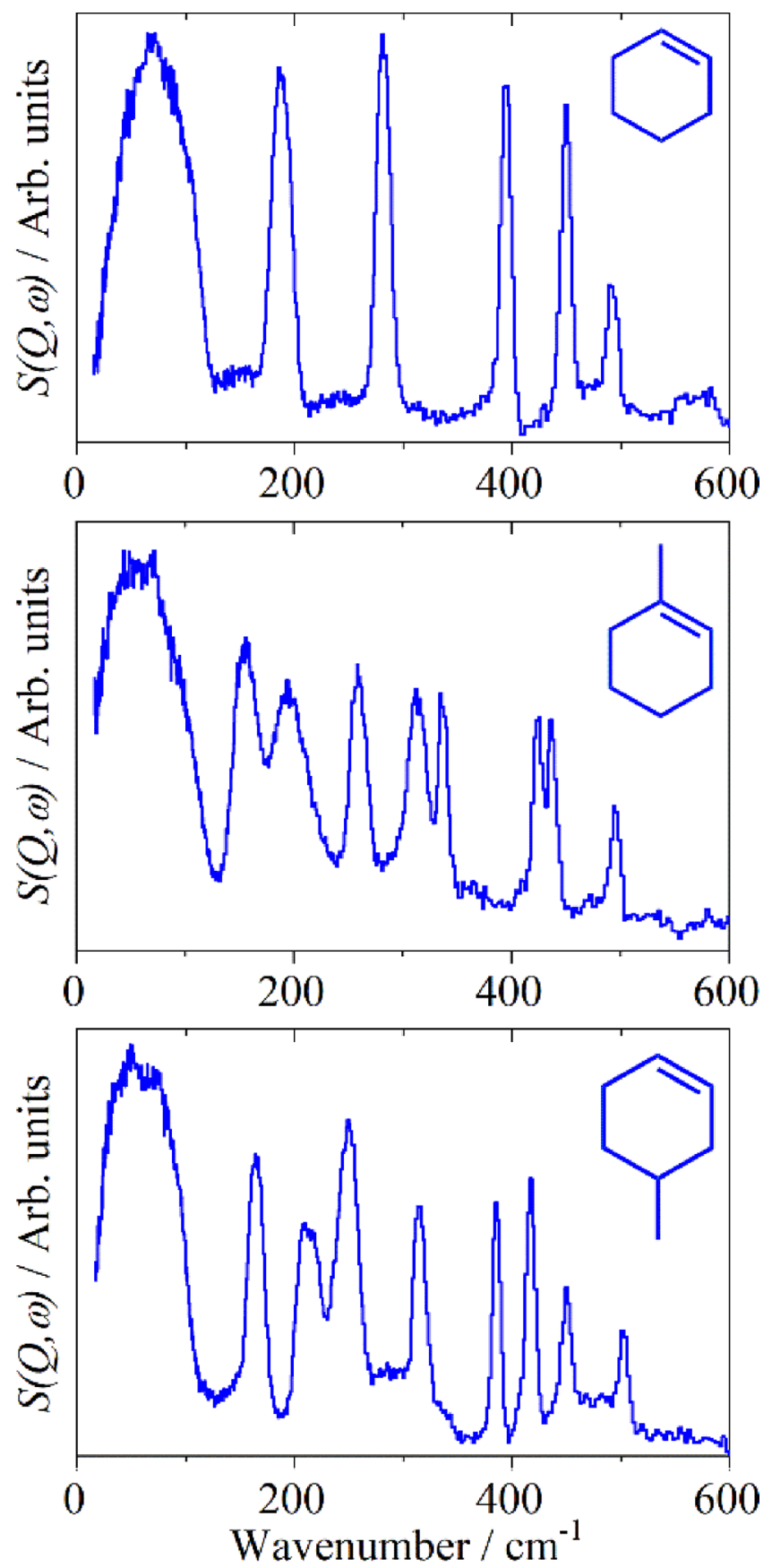

Figure 4. INS spectra at $<20 \mathrm{~K}$ of (top) cyclohexene, (middle) 1methylcyclohex-1-ene, and (bottom) 4-methylcyclohex-1-ene.

In benzene, all of the external (lattice) modes occur at $\leq 150$ $\mathrm{cm}^{-1}$ and this appears to be the case for all the isomeric methylated benzenes. ${ }^{9}$ Thus, modes above this energy must be related to the presence of the methyl group; note that in addition to the torsion, in-plane and out-of-plane (with respect to the aromatic ring) bending modes of the methyl group will also occur below $600 \mathrm{~cm}^{-1}$. (These are not the $\mathrm{C}-\mathrm{C}-\mathrm{H}$ bending modes which occur around $1400 \mathrm{~cm}^{-1}$, but $\mathrm{C}-\mathrm{C}-$ $\mathrm{Me}$, where the methyl $(=\mathrm{Me})$ group behaves approximately as a point mass).

On the assumption that the strongest features in the spectra are the methyl torsion(s), inspection of Figures 1-4 allows some patterns to be detected. In particular, for the methylated benzenes, molecules that have methyl groups that are not 
adjacent to another methyl group: toluene, $m$ - and $p$-xylene, and mesitylene, exhibit torsions at notably lower energy than those with adjacent methyl groups. Typically, nonadjacent methyls are at $\leq 100 \mathrm{~cm}^{-1}$, while adjacent methyls are at 150$200 \mathrm{~cm}^{-1}$. It is also apparent that there are modes that approach the methyl torsion in intensity, this is particularly the case for the tri- and tetramethylbenzenes.

To better understand these systems requires computational studies. As all the molecules are uncharged and have either zero or near-zero dipole moment, it follows that in the solid state, the dominant interactions are van der Waals forces. In these circumstances, it would be expected that isolated (i.e., gas phase) molecule calculations should provide a good description of the system. We have investigated hexamethylbenzene to test this idea.

Hexamethylbenzene was chosen because it is the only structure for which there is only one molecule in the primitive unit cell. ${ }^{21}$ Figure 5 compares the experimental spectrum with that calculated for the isolated molecule, the solid at the $\Gamma$ point and across the entire Brillouin zone, both with and without the Tkatchenko and Scheffler (TS) dispersion correction. From the top part of Figure 5, it can be seen that all the calculations are in reasonable agreement with the
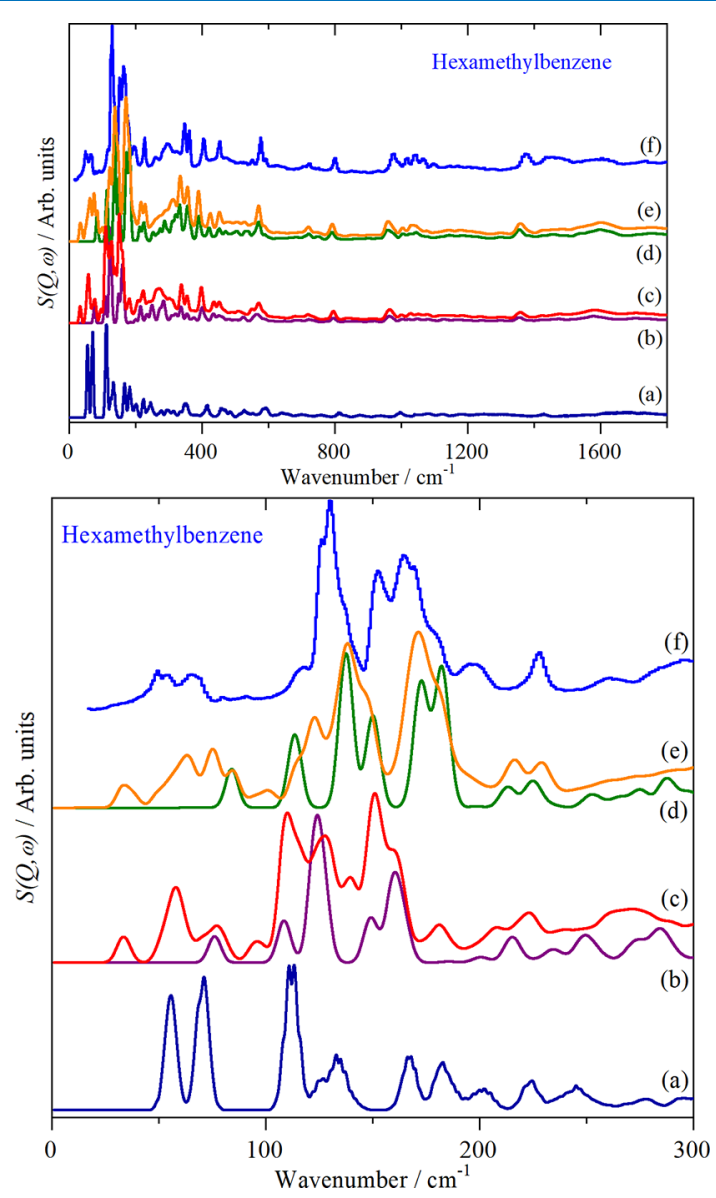

Figure 5. Comparison of observed and DFT calculated INS spectra of hexamethylbenzene. Top: $0-1800 \mathrm{~cm}^{-1}$ and lower: expanded view of the region containing the methyl torsions. (a) Isolated molecule (Gaussian), periodic-DFT (CASTEP) without the TS correction (b) at the $\Gamma$-point only, (c) for the complete Brillouin zone, periodic-DFT (CASTEP) with the TS correction (d) at the $\Gamma$-point only, and (e) for the complete Brillouin zone, (f) experimental spectrum. experimental spectrum, Figure 5f. However, inspection of the methyl torsion region, lower part of Figure 5, shows striking differences between the calculations. In particular, contrary to the expectation, the isolated molecule calculation, Figure 5a, shows very poor agreement in this region. The periodic calculations do better, but here there are marked differences between the $\Gamma$-point only and the complete Brillouin zone calculations: compare Figure 5 b,c and 5d,e.

The differences are evidence for significant vibrational dispersion (variation of transition energy with wavevector) in the system, as can be seen from the dispersion curves shown in Figure 6. Because INS is sensitive to all wavevectors and not

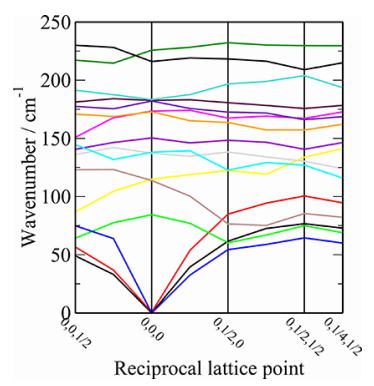

Figure 6. Dispersion curves calculated by CASTEP (with the TS correction) for hexamethylbenzene in the methyl torsion range.

just at the $\Gamma$-point as for infrared and Raman spectroscopy, the vibrational dispersion is directly reflected in the spectrum. The dispersion curves for the modes above $300 \mathrm{~cm}^{-1}$ are essentially flat and are shown in Figure S5. The dispersion arises from interactions between molecules in neighboring cells and, for nonpolar systems such as those discussed here, this is mediated by dispersion (i.e. van der Waals) forces and this is what we seek to include by using the TS correction. Therefore, as might have anticipated, the calculations that include the van der Waals correction, Figure 5d,e, show the best match between the observed and calculated spectra.

The complete Brillouin zone calculations demonstrate that the weak peaks at 52 and $66 \mathrm{~cm}^{-1}$ in the experimental spectrum are acoustic modes (Figures 5c,e and 6), (which are readily observable by INS spectroscopy). However, the mode visualizations of the Gaussian calculation show that the two lowest energy peaks are the torsions, whereas the periodicDFT calculations show the torsions to be the intense peaks between 100 and $150 \mathrm{~cm}^{-1}$. This is a clear failure of the isolated molecule approximation.

All of the calculations were carried out at the experimental lattice parameters. Repeating the calculation (including the TS correction) allowing these to optimize resulted in a negligible $(-0.8 \%)$ change in cell volume, which is unsurprising as the structure was determined at $5 \mathrm{~K}^{21}$ Consequently, the INS spectrum generated from the vibrational calculation using this structure was almost identical to that which used the experimental lattice parameters.

Even with the TS correction, there is no exact agreement. This probably has several contributions. The absolute accuracy of density functional theory (DFT) calculations of vibrational transition energies for gas phase molecules has been extensively investigated (e.g., refs 26 and 27 and reviewed in ref 28). For molecules with more than 10 or so atoms, the vibrational modes are usually accurate to around $\pm 10 \mathrm{~cm}^{-1}$ (typically they are underestimated). For periodic systems, 
Table 1. Observed, as-Calculated at the Brillouin Zone $\Gamma$-Point (in Brackets) and for the Isolated Molecule, Transition Energies of the Methyl Torsion in Unsaturated Molecules ${ }^{a}$

\begin{tabular}{|c|c|c|c|c|c|c|}
\hline \multirow{2}{*}{$\begin{array}{c}\text { compound } \\
\text { methylated benzenes }\end{array}$} & \multicolumn{3}{|c|}{ methyl torsion transition energies $/ \mathrm{cm}^{-1}$} & \multirow[b]{2}{*}{$\begin{array}{l}\text { space } \\
\text { group }\end{array}$} & \multirow[b]{2}{*}{$Z$} & \multirow[b]{2}{*}{ refs } \\
\hline & experimental & CASTEP & Gaussian & & & \\
\hline 1-methylbenzene (toluene) & 47 & $112,115,116,118,119,127,127,127$ & 38 & $P 2_{1} / c$ & 4 & 17 \\
\hline 1,2-dimethylbenzene (ortho-xylene) & $\begin{array}{l}147,156,178 \\
193\end{array}$ & $164,168,169,174,176,184,185,195$ & 130,170 & $\mathrm{P} 2_{1} / a$ & 4 & 18 \\
\hline 1,3-dimethylbenzene (meta-xylene) & 56 & $\begin{array}{l}114,116,119,122,124,125,130,130,130,132,136 \\
\quad 138,139,139,140,145\end{array}$ & 28,37 & $\mathrm{Pbca}^{b}$ & 8 & 19 \\
\hline 1,4-dimethylbenzene (para-xylene) & 124,133 & $102,111,118,140$ & 35,50 & $P 2_{1} / n$ & 2 & 19 \\
\hline 1,2,3-trimethylbenzene & 186 & & $72,176,186$ & unknown & & \\
\hline 1,2,4-trimethylbenzene & 175,196 & & $42,138,171$ & unknown & & \\
\hline \multirow[t]{2}{*}{ 1,3,5-trimethylbenzene(mesitylene) } & 151,156 & $\begin{array}{l}116,116,116,120,120,122,122,122,136,148,148 \text {, } \\
\quad 148\end{array}$ & $238,239,239$ & $P \overline{1}$ & 4 & 20 \\
\hline & & $\begin{array}{l}124,132,134,137,145,145,150,152,157,175,178 \\
180\end{array}$ & & $P 2{ }_{1} 3^{b}$ & 4 & 20 \\
\hline 1,2,3,4-tetramethylbenzene & $\begin{array}{l}169,200,210 \\
218\end{array}$ & & $\begin{array}{l}61,142,192 \\
193\end{array}$ & unknown & & \\
\hline 1,2,3,5-tetramethylbenzene & 178 & & $\begin{array}{l}19,51,178 \\
199\end{array}$ & unknown & & \\
\hline 1,2,4,5-tetramethylbenzene(durene) & $\begin{array}{l}148,158,167 \\
182,195\end{array}$ & $148,153,167,173,173,177,197,197$ & $\begin{array}{l}130,132,169 \\
197\end{array}$ & $P 2_{1} / a$ & 2 & 14 \\
\hline pentamethylbenzene & $\begin{array}{l}81,106,124 \\
203,210,228\end{array}$ & $93,97,128,132,138,139,211,225,227,229$ & $\begin{array}{l}23,152,156 \\
189,208\end{array}$ & $P \overline{1}$ & 2 & 15 \\
\hline \multirow[t]{2}{*}{ hexamethylbenzene } & $\begin{array}{l}126,130,152 \\
165,170,179\end{array}$ & $137,138,150,172,173,182$ & $\begin{array}{l}55,70,70 \\
111,111 \\
113\end{array}$ & $P \overline{1}$ & 1 & 21 \\
\hline & & Methylated Polycyclic Aromatics & & & & \\
\hline 1-methylnaphthalene & 38 & & 193 & unknown & & \\
\hline 2,3-dimethylnaphthalene & 172,228 & & 144,197 & $P 2_{1} / c^{b}$ & 2 & 22 \\
\hline 9-methylanthracene & 102 & $88,96,99,99$ & 20 & $P 2_{1} / c$ & 4 & 23 \\
\hline \multirow[t]{2}{*}{ 9,10-dimethylanthracene } & $53,60,69,73$ & $100,120,122,122$ & $c$ & $P 2_{1} / c^{b}$ & 2 & 24 \\
\hline & & Methylated Cyclic Alkenes & & & & \\
\hline $\begin{array}{l}\text { 1,2,3,4-tetramethyl-1,3-cyclopentadiene } \\
(85 \%)\end{array}$ & $\begin{array}{l}196,201,208 \\
215\end{array}$ & & $\begin{array}{l}101,108,155 \\
179\end{array}$ & unknown & & \\
\hline 1,2,3,4,5-pentamethyl-1,3-cyclopentadiene & $\begin{array}{l}128,137,168 \\
202,266\end{array}$ & $\begin{array}{l}120,124,126,130,162,164,165,165,177,178,181 \\
181,185,185,190,191,254,255,264,266\end{array}$ & $\begin{array}{l}112,127,145 \\
168,279\end{array}$ & $P 2_{1} 2_{1} 2_{1}$ & 4 & 25 \\
\hline 1-methylcyclohex-1-ene & 194 & & 182 & unknown & & \\
\hline 4-methylcyclohex-1-ene & 250 & & 237 & unknown & & \\
\hline
\end{tabular}

${ }^{a}$ If known, the space group and number of molecules in the primitive cell $(Z)$ are also given. ${ }^{b}$ The space group probably does not correspond to the phase obtained. ${ }^{c}$ Unable to obtain all real modes.

there has been much less work, but a recent study of resorcinol ${ }^{29}$ had similar errors (excluding the $\mathrm{C}-\mathrm{H}$ and $\mathrm{O}-\mathrm{H}$ stretch regions that are strongly affected by anharmonicity). This accords with our own experience for a variety of systems, for example, refs 30-33 The crucial factor is that the errors are apparently random and are not a simple fraction of the transition energy. Thus, in the top part of Figure 5, there is a mode calculated at $1360 \mathrm{~cm}^{-1}$ and observed at $1376 \mathrm{~cm}^{-1}$ (a $1.1 \%$ difference) but this is more than close enough that the assignment is unambiguous. However, in the region below 300 $\mathrm{cm}^{-1}$ errors of this size are relatively much larger, $\sim 10 \%$, and this makes the comparison appear poorer. As stated elsewhere: 29 "calculations of the low-energy transfer range are challenging from the technical point of view because all the numerical errors accumulate here." We also note that the TS correction is a semi-empirical approach, it is possible that there is still room for improvement.

In the remainder of the paper, the procedure adopted was to carry out full dispersion calculations based on structures that had been geometry optimized (including the TS correction) at the experimental lattice parameters. Table 1 lists the observed and calculated methyl torsion modes for the molecules considered here. For those systems, where the structure is not known, the strongest modes in the low-energy region are assumed to be the torsions. Where available, the calculated spectra are shown as part of the full range spectra in the ESI. We will briefly consider a few specific molecules that are of particular interest.

Toluene. At ambient pressure, in the solid state, toluene can be prepared as an amorphous phase and two crystalline phases, $\alpha$ and $\beta .^{34}$ The $\alpha$-phase is readily prepared on cooling liquid toluene and is the phase observed here.

The torsional mode in toluene has been extensively investigated in both the gas phase $\mathrm{s}^{35-38}$ and the solid state. $^{39-41}$ In the gas phase, the methyl group undergoes almost free rotation ${ }^{35}$ - the barrier is $<10 \mathrm{~cm}^{-1}$ - and this leads to a description in terms of rotor and vib-rotor states. $^{36-38}$ The torsional energies vary as $m^{2} F$, where $m$ is the torsional quantum number and $F$ is the effective rotational constant. As the torsional barrier increases, then these energy levels evolve into torsional vibrational energies. In the solid, the torsional motion has become trapped and this is what is measured by INS. Because the molecule is cold and not irradiated, then the molecules will be in their lowest torsional 
levels: this would be $m=0,1$ in the gas-phase for a fairly free rotor, and $v=0$ for a heavily hindered rotor in the solid state. In previous work, ${ }^{39,40}$ the methyl torsion has been assigned to the strong feature at $47 \mathrm{~cm}^{-1}$. Figure 7 shows the INS spectra

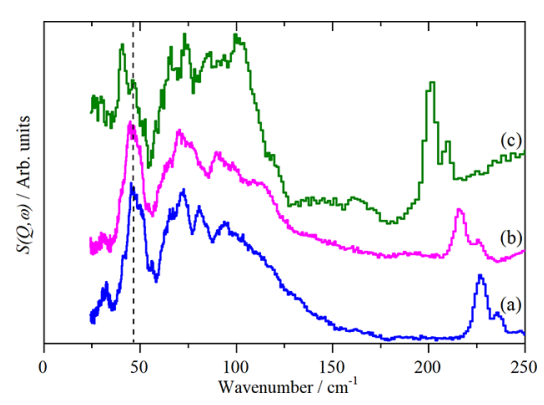

Figure 7. INS spectra of toluene isotopomers in the low-energy region. (a) $\mathrm{C}_{6} \mathrm{H}_{5} \mathrm{CH}_{3}$, (b) $\mathrm{C}_{6} \mathrm{D}_{5} \mathrm{CH}_{3}$, and (c) $\mathrm{C}_{6} \mathrm{D}_{5} \mathrm{CD}_{3}$. The dashed vertical line shows the position of the methyl torsion.

of $\mathrm{C}_{6} \mathrm{H}_{5} \mathrm{CH}_{3}, \mathrm{C}_{6} \mathrm{D}_{5} \mathrm{CH}_{3}$, and $\mathrm{C}_{6} \mathrm{D}_{5} \mathrm{CD}_{3}$ in the low-energy region. The mode at $225 \mathrm{~cm}^{-1}$, shown in Figure $7 \mathrm{a}$, that progressively downshifts is the methyl out-of-plane bend. In contrast, it can be seen that the strong mode at $47 \mathrm{~cm}^{-1}$ (indicated by the dashed line) is almost invariant for $\mathrm{C}_{6} \mathrm{H}_{5} \mathrm{CH}_{3}$ and $\mathrm{C}_{6} \mathrm{D}_{5} \mathrm{CH}_{3}$ but undergoes a marked downshift to $41 \mathrm{~cm}^{-1}$ for $\mathrm{C}_{6} \mathrm{D}_{5} \mathrm{CD}_{3}$. The $\mathrm{D} / \mathrm{H}$ ratio of the transition energies is 0.87 , somewhat larger than the 0.71 expected from the ratio of the masses. We will return to this point later.

However, the unit cell of toluene is complex and includes eight molecules, thus there should be eight torsional transition energies. The peak at $47 \mathrm{~cm}^{-1}$ has several sub-maxima, which probably accounts for some of the modes. Unfortunately, the calculations are not helpful here, as they predict the torsional modes at $115-127 \mathrm{~cm}^{-1}$, see Figure S2. However, they do show that there is mixing between the torsion and the external modes (because they have common symmetry representations in this space group). This is likely to be the case for the real material, even though the torsions are at a lower energy than calculated, they still fall within the external density of states. Thus, the torsions are not pure modes and the isotopic shift is smaller than what the mass change predicts.

Xylenes. The structures of all three isomeric 1,2dimethylbenzenes (xylenes) have been determined at low temperature by neutron diffraction. ${ }^{18,19}$ For ortho and paraxylene, the observed and calculated spectra are in reasonable agreement, although the torsional transition energy is somewhat overestimated in ortho-xylene (see Figure S3 and Table 1). For para-xylene, the calculation of the vibrational transition energies at the $\Gamma$-point of the Brillouin zone gave all real modes, however, the full vibrational dispersion produced several imaginary modes away from the $\Gamma$-point. Repeating the geometry optimization with the same convergence criteria but also allowing the lattice parameters to optimize resulted in only a $0.46 \%$ change in the cell volume but with real modes across the entire Brillouin zone. For meta-xylene, there is a marked disagreement between theory and observation, Figure 8a,b. The large discrepancy between the observed and calculated spectra for meta-xylene, suggests that we have obtained a different phase from that determined by neutron diffraction. ${ }^{19}$

Mesitylene. 1,3,5-Trimethylbenzene (mesitylene) has three solid state phases, all of which can be obtained at 10 $\mathrm{K}^{11,20}$ Comparison with the literature spectra ${ }^{11,42}$ shows that

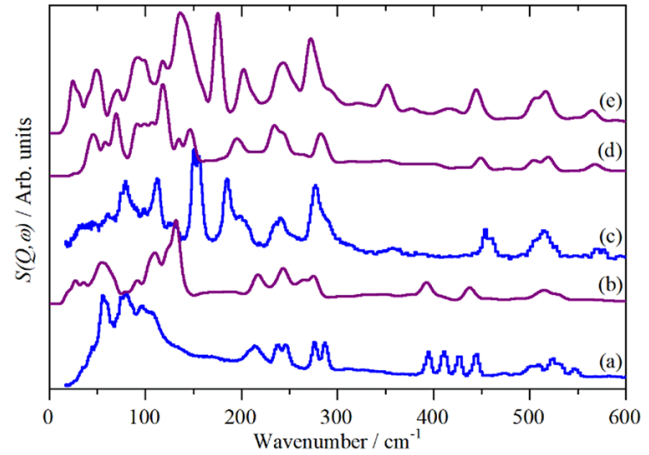

Figure 8. Observed (a) and calculated by CASTEP and (b) INS spectra of meta-xylene. Observed INS spectrum of mesitylene (c), calculated by CASTEP for phase I $(P 2,3)(\mathrm{d})$, and for phase III $(P \overline{1})$ (e).

we have obtained the low-temperature phase III. Only the cubic phase I has been fully characterized crystallographically ${ }^{20}$ and comparison of the spectrum calculated from this phase, as expected, gives very poor agreement with the experimental spectrum, Figure $8 \mathrm{c}$,d. As noted previously, ${ }^{11,42}$ there is a very large effect on the methyl torsional modes on going from phase III $\rightarrow$ phase I.

Only the lattice constants are known for phase III which may be either $P 1$ or $P \overline{1}$. However, it is closely related to the monoclinic phase II, which has four molecules in the primitive cell, with disordered methyl groups. ${ }^{20}$ To attempt to model phase III, phase II was distorted to the lattice parameters of phase II and $P \overline{1}$ symmetry imposed, that is, ordered methyl groups. Both the geometry and lattice parameters were then allowed to optimize. This resulted in an almost monoclinic cell. To prevent this, the system was geometry and lattice optimized but only the cell lengths were allowed to change, the angles were held at the experimental values. This converged to a result with a $3 \%$ volume expansion. Calculation of the INS spectrum based on this structure, Figure $8 \mathrm{e}$, shows reasonable agreement with the experimental spectrum, suggesting that it is a good approximation to the actual structure. Figure S26 shows the calculated structure and Table S2 the corresponding cif file.

Intra-vs Intermolecular Effects in the Methylbenzenes. It is apparent from the preceding discussion that both intramolecular (the number of methyl groups per benzene molecule) and intermolecular (the presence of neighboring molecules whether in the same unit cell or in adjacent ones) effects both play a significant role in determining the methyl torsion transition energy. For the methylbenzenes, we believe it is possible to, at least partially, disentangle these undoubtedly cooperative effects. We consider the intermolecular effect first. Figure 9 shows the average of the six methyl torsion transition energies of hexamethylbenzene as a function of the shortest intermolecular distance (in all cases this is a $\mathrm{H} \cdots \mathrm{H}$ contact). It can be seen that the average calculated and observed transition energies are in good agreement and that even a modest increase from $2.367 \AA$ in the real system to $4.256 \AA$ results in a sharp decrease of the transition energy. Increasing the distance further shows a small effect. These calculations were carried out with the plane-wave code CASTEP; calculation of the isolated molecule with Gaussian shows only a further small decrease. This suggests that although the two codes use very different methodologies the limiting transition energies are essentially the same and that we can use the Gaussian values as the limiting case. 


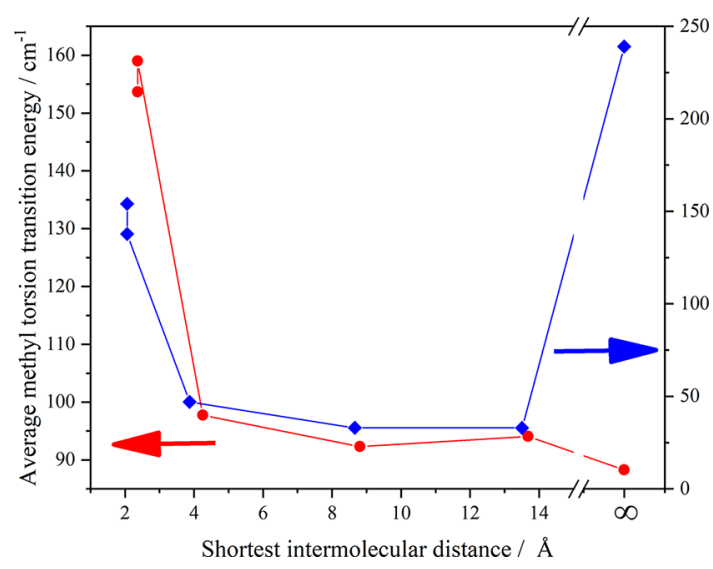

Figure 9. Comparison of the average methyl torsion transition energy of hexamethylbenzene (red dots) and mesitylene (blue diamonds) as a function of the shortest intermolecular contact. The first two points are the observed and calculated transition energies for the molecule at the experimental lattice parameters. The last point on the extreme right for both compounds is a Gaussian calculation for the isolated molecule. The solid lines are a guide to the eye.

Figure 10 shows a comparison of the average methyl torsion transition energy of the methylbenzenes as a function of the

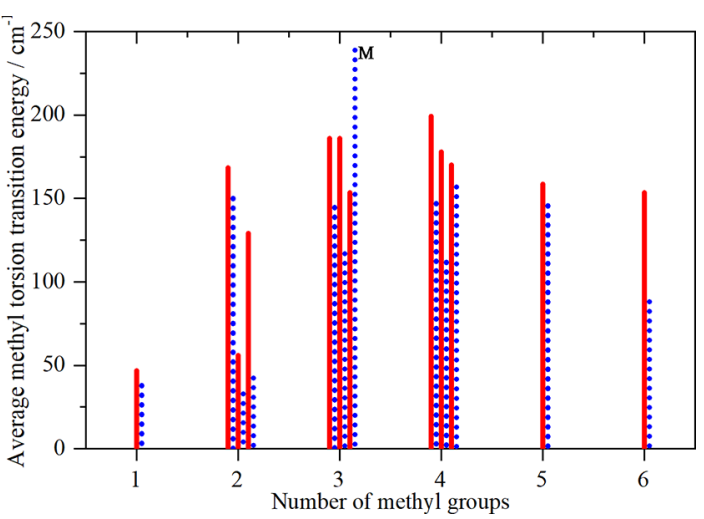

Figure 10. Average methyl torsion transition energy of the methylbenzenes as a function of the number of methyl groups. The solid lines are the experimental values and the dotted lines are for a Gaussian calculation of the isolated molecule. " $\mathrm{M}$ " is the calculated transition energy for mesitylene.

number of methyl groups. In all cases (except for mesitylene, indicated by $M$ in Figure 10), the presence of intermolecular interactions increases the average energy by at least $8 \%$ and in several cases by more than 50\%. Mesitylene is clearly anomalous. Multiple attempts with both Gaussian and CASTEP only resulted in all real modes for the internal modes when symmetry was imposed on the molecule. Figure 9 also shows the results for mesitylene. With CASTEP it follows the same trend as hexamethylbenzene: a rapid fall-off with distance to an asymptotic value $\left(33 \mathrm{~cm}^{-1}\right)$; however, the same $C_{3 h}$ structure with Gaussian results in an average value of 239 $\mathrm{cm}^{-1}$. We have no explanation for this behavior, however, we believe that the CASTEP result is the correct one, as there is no apparent reason for mesitylene to be exceptional. Figure 10 also sheds light on the intramolecular effect (the number of methyl groups). It is apparent that, generally, adjacent methyl groups have transition energies in the range $150-200 \mathrm{~cm}^{-1}$, while isolated methyls occur at lower energy.
Methylnaphthalenes. Figure 11 compares the INS spectra of naphthalene, 1-methylnaphthalene, and 2,3-

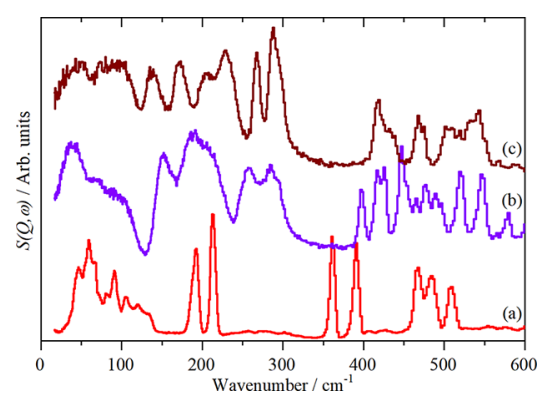

Figure 11. INS spectra of: (a) naphthalene, (b) 1-methylnaphthalene, and (c) 2,3-dimethylnaphthalene.

dimethylnaphthalene. It is not at all clear which features are the torsional modes in the methylnaphthalenes. Computational studies are not helpful here; the structure of 1-methylnaphthalene is not known and that of 2,3-dimethylnaphthalene is only known for a disordered room temperature phase, ${ }^{22}$ only the lattice parameters are known for the low-temperature phases. ${ }^{43} 1$-methylnaphthalene is liquid at room temperature and it is possible that the broad features in the low-energy region indicate that it was quenched to a glass rather than a crystal.

The lattice modes of naphthalene occur below $150 \mathrm{~cm}^{-1}$, so it is reasonable to assume that any bands above this energy are internal modes in the methylnaphthalenes. 1-Methylnaphthalene is analogous to toluene, so a similar torsional energy might be expected. There is an apparent excess of intensity at 38 $\mathrm{cm}^{-1}$ as compared to naphthalene, so this is tentatively assigned to the torsion. Similarly, 2,3-dimethylnaphthalene is analogous to ortho-xylene, where the modes occur in the range $150-200 \mathrm{~cm}^{-1}$ (Table 1), thus the bands in the same region of 2,3-dimethylnaphthalene at 172 and $228 \mathrm{~cm}^{-1}$ are so assigned. A low resolution data set $^{44}$ assigned the mode at $210 \mathrm{~cm}^{-1}$; however, as we have seen for mesitylene, the local environment has a major influence on the torsional energy and these assignments are provisional. Knowledge of the low-temperature crystal structures would be useful, but selective isotopic labeling, as done for toluene, is the only reliable method to determine the transition energies unambiguously.

Methylanthracenes. Figure 2 shows the INS spectra of 9methylanthracene and 9,10-dimethylanthracene. Unexpectedly, the spectra are markedly different. In 9-methylanthracene the torsion occurs at $102 \mathrm{~cm}^{-1}$, in good agreement with that calculated (Figure S18 and Table 1). In 9,10-dimethylanthracene, the torsions are observed at much lower energy, whereas they are calculated at similar energies to 9methylanthracene (Figure S19 and Table 1). Again, the disagreement suggests that a low-temperature phase exists, as both structural determinations were made at room temperature. $^{24,45}$ In some respects, it is 9-methylanthracene, that is, anomalous, as isolated rotors (cf. toluene) are expected at low energy, as seen for 9,10-dimethylanthracene.

Methylated Cycloalkenes. The spectra of tetra- and pentamethylcyclopentadiene, Figure 3, are generally similar. The tetramethylcyclopentadiene sample is $\sim 85 \% \quad 1,2,3,4-$ tetramethyl-1,3-cyclopentadiene, so this will dominate the spectrum. In this case, all the methyl groups are bonded to $\mathrm{sp}^{2}$ carbon atoms and the torsional modes must be assigned to the 
intense feature centered at $201 \mathrm{~cm}^{-1}$. The calculated spectrum of pentamethylcyclopentadiene is shown in Figure S21 and is in reasonable agreement with the experimental spectrum. In this case, four methyl groups are bonded to $\mathrm{sp}^{2}$ carbon atoms and the fifth to a $\mathrm{sp}^{3}$ carbon atom. The presence of four molecules in the primitive cell means that there are 20 torsional modes, interestingly there is a distinct division between the $\mathrm{sp}^{2}$ - and the $\mathrm{sp}^{3}$-bonded methyls: the former occur at or below $\sim 200 \mathrm{~cm}^{-1}$ and the latter at $266 \mathrm{~cm}^{-1}$.

The solid state behavior of cyclohexene is complex, with several phases known, both ordered and glassy. ${ }^{46}$ Quenching the liquid from room temperature in liquid nitrogen, as was done here, results in a glass, and shown by the featureless density of states below $130 \mathrm{~cm}^{-1}$, as shown in Figure 4. The two methylcyclohexenes show a similar "lump" and are, presumably, also glasses. In these circumstances, it might be hoped that isolated molecule calculations would be useful because the local environment should be homogeneous: the specific intermolecular interactions that appear to be crucial factors in determining the methyl torsional energy are averaged out. As can be seen in Figure 12, these expectations are met;

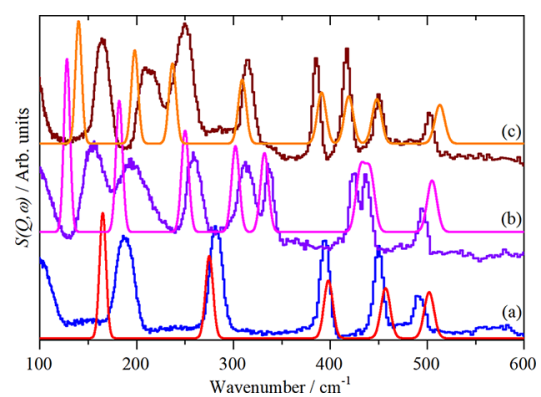

Figure 12. Observed (stepped line) and calculated by Gaussian (continuous line) INS spectra of: (a) cyclohexene, (b) 1methylcyclohex-1-ene, and (c) 4-methylcyclohex-1-ene e.

the calculated spectra are in reasonable agreement with the experimental data and certainly good enough to enable assignments to be made. The mode animations show that the torsion is calculated at $182 \mathrm{~cm}^{-1}\left(194 \mathrm{~cm}^{-1}\right.$ observed $)$ and $237 \mathrm{~cm}^{-1}\left(250 \mathrm{~cm}^{-1}\right.$ observed $)$ in 1-methyl- and 4methylcyclohex-1-ene respectively. The separation between methyls bonded to $\mathrm{sp}^{2}\left(\leq 200 \mathrm{~cm}^{-1}\right)$ and the $\mathrm{sp}^{3}\left(\sim 250 \mathrm{~cm}^{-1}\right)$ carbon atoms noted for the methylcyclopentadienes also applies here.

Methyl Rock and $\mathrm{C}-\mathrm{H}$ Bend Modes. While the focus of this paper is the methyl torsion, we will also briefly discuss the methyl rock and $\mathrm{C}-\mathrm{H}$ bend modes. Figure 13 shows the region that includes these modes for all the methylated benzenes. It can be seen that the methyl rock (expected in the range $\left.800-1000 \mathrm{~cm}^{-1}\right)^{2-4}$ does not give rise to easily distinguished modes. The methyl $\mathrm{C}-\mathrm{H}$ bend modes are more interesting. It can be seen that for molecules with three or less methyl groups (Figure 13a-g) it is difficult to pick out these modes. In contrast, for the systems with four or more methyl groups (Figure $13 \mathrm{~h}-\mathrm{l}$ ), the symmetric $\left(1375 \mathrm{~cm}^{-1}\right.$ ) and asymmetric $\left(1445 \mathrm{~cm}^{-1}\right)$ modes are clearly seen.

\section{CONCLUSIONS}

In this paper, we have investigated how the methyl torsion transition energy in unsaturated systems is affected by its environment. It has become apparent that it is strongly

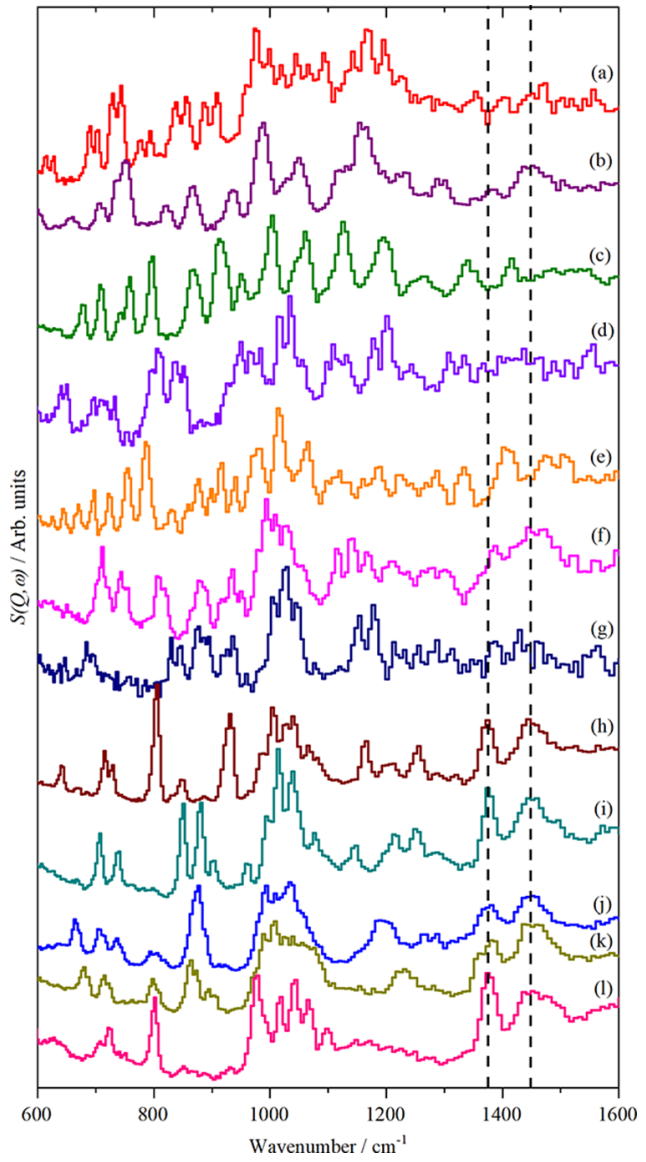

Figure 13. INS spectra of the methylated benzenes, $\mathrm{C}_{6} \mathrm{H}_{6-x}\left(\mathrm{CH}_{3}\right)_{x}(x$ $=1-6)$.in the region of the methyl rock and $\mathrm{C}-\mathrm{H}$ bend modes of: (a) toluene, (b) meta-xylene, (c) ortho-xylene, (d) para-xylene, (e) 1,2,3trimethylbenzene, (f) 1,2,4-trimethylbenzene, (g) mesitylene, (h) 1,2,3,4-tetramethylbenzene, (i) 1,2,3,5-tetramethylbenzene, (j) durene, (k) pentamethylbenzene, and (l) hexamethylbenzene. The vertical dashed lines show the position of the symmetric $\left(1375 \mathrm{~cm}^{-1}\right)$ and asymmetric $\left(1445 \mathrm{~cm}^{-1}\right)$ methyl $\mathrm{C}-\mathrm{H}$ bending modes.

influenced by both intramolecular interactions (the number of methyl groups present in the molecule) and the intermolecular interactions. For the former, there is a general pattern that isolated methyl groups occur at lower wavenumber, typically $<100 \mathrm{~cm}^{-1}$, and polymethylated species at $\sim 100-200 \mathrm{~cm}^{-1}$, although there are exceptions. There also appears to be a pattern that methyl groups bonded to $\mathrm{sp}^{2}$ carbon atoms occur at $\leq 200 \mathrm{~cm}^{-1}$ and those bonded to $\mathrm{sp}^{3}$ carbon atoms occur at $\sim 250 \mathrm{~cm}^{-1}$, as found for the $n$-alkanes. ${ }^{6-8}$

The biggest surprise from this work is that the intermolecular interactions have a major influence on the torsion transition energy, as demonstrated unambiguously elsewhere for mesitylene ${ }^{11,39}$ and also seen here for all the other methylbenzenes. The interactions result in the torsional transition energy being raised by at least $8 \%$, as compared to the isolated molecule, and often much more. In part, this may be caused by the fact that the methyl torsion is rarely a pure mode (unless enforced by symmetry). It occurs in the lattice (translational and librational) mode region and, for polycyclic aromatic species, where the whole-body out-of-plane deformations occur. The extent of the mixing with these would make the torsional mode dependent on its immediate neighbors.

The agreement between the observed and CASTEP calculated spectra is generally good, although not perfect, 
toluene being a case in point, and highlights just how demanding it is to obtain accurate transition energies for low energy modes. The disagreement between the observed and calculated INS spectra for meta-xylene and 9,10-dimethylanthracene is so severe that it would suggest that there are additional phases to those presently known.

\section{EXPERIMENTAL SECTION}

The compounds were obtained from commercial sources (see Table S1 of the Supporting Information) and used as received. Liquid samples were loaded into $1 \mathrm{~mm}$ pathlength indium wire-sealed $\mathrm{Al}$ sample holders, solid samples were wrapped in aluminium foil. Sample masses ranged from 0.5-3.4 g. The INS spectra were recorded at $\leq 20 \mathrm{~K}$ using a broad band highresolution spectrometer TOSCA ${ }^{47}$ at the ISIS Pulsed Neutron and Muon Facility (Oxfordshire, UK). ${ }^{48}$

Computational Methods. Isolated molecule DFT calculations were performed with Gaussian 09. ${ }^{49}$ The B3LYP functional with the 6-311G(d) basis set was used in all cases. Periodic DFT calculations were carried out with the plane wave pseudopotential program CASTEP. ${ }^{50}$ The geometry optimization used the generalized gradient $\mathrm{PBE}^{51}$ functional together with the TS dispersion correction. ${ }^{52}$ The plane wave cutoff was $750 \mathrm{eV}$, and the forces were converged to better than $|0.01| \mathrm{eV} \AA^{-1}$, the $k$-point grid used depended on the initial structure and is given in Table S1. The vibrational spectra at the $\Gamma$-point in the Brillouin zone were calculated using density functional perturbation theory. ${ }^{53}$ Phonon dispersion was calculated along high-symmetry directions throughout the Brillouin zone. Dynamical matrices were computed on a regular grid of wavevectors throughout the Brillouin zone and Fourier interpolation was used to extend the computed grid to the desired fine set of points along the high-symmetry paths. The initial structures were taken from the Cambridge Structural Database, ${ }^{54}$ the refcodes are included in Table S1. Calculated INS spectra were generated from the Gaussian or CASTEP output using ACLIMAX ${ }^{55}$ or AbINS. $^{56}$

\section{ASSOCIATED CONTENT}

\section{(s) Supporting Information}

The Supporting Information is available free of charge at https://pubs.acs.org/doi/10.1021/acsomega.9b03351.

Table of the source of the compounds and details of the CASTEP calculations, INS spectra of the compounds in the $0-1800 \mathrm{~cm}^{-1}$ range and the spectra as calculated by CASTEP, table of the structure suggested for mesitylene phase III in cif format (PDF)

\section{AUTHOR INFORMATION}

\section{Corresponding Author}

Stewart F. Parker - School of Chemistry, University of Glasgow, Glasgow G12 8QQ, U.K.; UK Catalysis Hub, Research Complex at Harwell and ISIS Neutron and Muon Source, STFC Rutherford Appleton Laboratory, Oxon OX11 OFA, U.K.; $\odot$ orcid.org/0000-0002-3228-2570; Phone: +44 (0) 1235 446182; Email: stewart.parker@stfc.ac.uk

\section{Authors}

Andrea Zachariou - School of Chemistry, University of Glasgow, Glasgow G12 8QQ U.K.; UK Catalysis Hub,
Research Complex at Harwell, STFC Rutherford Appleton Laboratory, Oxon OX11 OFA, U.K.

Alexander P. Hawkins - School of Chemistry, University of Glasgow, Glasgow G12 8QQ, U.K.; UK Catalysis Hub, Research Complex at Harwell, STFC Rutherford Appleton Laboratory, Oxon OX11 OFA, U.K.

Paul Collier - Johnson Matthey Technology Centre, Reading RG4 9NH, U.K.

Russell F. Howe - Department of Chemistry, University of Aberdeen, Aberdeen AB24 3UE, U.K.; ○ orcid.org/00000003-2462-8962

David Lennon - School of Chemistry, University of Glasgow, Glasgow G12 8QQ, U.K.; UK Catalysis Hub, Research Complex at Harwell, STFC Rutherford Appleton Laboratory, Oxon OX11 OFA, U.K.; $\odot$ orcid.org/0000-0001-8397-0528

Complete contact information is available at:

https://pubs.acs.org/10.1021/acsomega.9b03351

\section{Notes}

The authors declare no competing financial interest.

The INS spectra as measured in time-of-flight binary format are at $10.5286 /$ ISIS.E.RB1810859. The data (INS spectra as ASCII files in energy transfer, input, and output files for the Gaussian and CASTEP calculations, INS spectra generated from these outputs) that supports this work is at 10.5286/ edata/736 (2019). The INS spectra are available from the INS database at: http://wwwisis2.isis.rl.ac.uk/INSdatabase/.

\section{ACKNOWLEDGMENTS}

The STFC Rutherford Appleton Laboratory is thanked for funding and access to neutron beam facilities. Computing resources (time on the SCARF compute cluster for the CASTEP calculations) was provided by STFC's e-Science facility. Dr John Tomkinson (ISIS) is thanked for generously providing the INS spectra of the toluene isotopomers. A.Z. and A.P.H. would like to thank Johnson Matthey plc. For financial support through the provision of industrial CASE studentships in partnership with the EPSRC. The UK Catalysis Hub is kindly thanked for resources and support provided via our membership of the UK Catalysis Hub Consortium and funded by EPSRC grant: EP/R026939/1, EP/R026815/1, EP/ R026645/1, EP/R027129/1 or EP/M013219/1(biocatalysis).

\section{REFERENCES}

(1) Thomas, N. C. The early history of spectroscopy. J. Chem. Educ. 1991, 68, 631-634.

(2) Bellamy, L. The Infrared Spectra of Complex Molecules; Chapman and Hall: London; Vol. 1, 1975.

(3) Lin-Vien, D.; Colthup, N. B.; Fateley, W. G.; Grasselli, J. G. The Handbook of Infrared and Raman Characteristic Frequencies of Organic Molecules; Academic Press, 1991.

(4) Colthup, N. B.; Daly, L. H.; Wiberley, S. E. Introduction to Infrared and Raman Spectroscopy, 3rd ed.; Academic Press: Boston, 2012.

(5) Mitchell, P. C. H.; Parker, S. F.; Ramirez-Cuesta, A. J.; Tomkinson, J. Vibrational Spectroscopy with Neutrons, with Applications in Chemistry, Biology, Materials Science and Catalysis; World Scientific: Singapore, 2005.

(6) Parker, S. F.; Braden, D. A.; Tomkinson, J.; Hudson, B. S. The full LAM spectrum of an $n$-alkane: Comparison of observed and computed incoherent inelastic neutron scattering spectrum of $\mathrm{n}$ octadecane,. J. Phys. Chem. B 1998, 102, 5955-5956.

(7) Braden, D. A.; Parker, S. F.; Tomkinson, J.; Hudson, B. S. Inelastic neutron scattering spectra of the longitudinal acoustic modes 
of the normal alkanes from pentane to pentacosane. J. Chem. Phys. 1999, 111, 429-437.

(8) Tomkinson, J.; Parker, S. F.; Braden, D. A.; Hudson, B. S. Inelastic neutron scattering spectra of the transverse acoustic modes of the normal alkanes. Phys. Chem. Chem. Phys. 2002, 4, 716-721.

(9) Kearley, G. J.; Johnson, M. R.; Tomkinson, J. Intermolecular interactions in solid benzene. J. Chem. Phys. 2006, 124, 044514.

(10) Cavagnat, D.; Lascombe, J.; Lassegues, J. C.; Horsewill, A. J.; Heidemann, A.; Suck, J. B.; Suck, J. B. Neutron and Raman scattering studies of the methyl dynamics in solid toluene and nitromethane. J. Phys. 1984, 45, 97-105.

(11) Natkaniec, I.; Holderna-Natkaniec, K.; Kalus, J. Neutron scattering studies of methyl derivatives of benzene selected as potential materials for cold neutron moderators. Physica B 2004, 350, e651-e653.

(12) Kalus, J.; Monkenbusch, M.; Natkaniec, I.; Prager, M.; Wolfrum, J.; Wörlen, F. Neutron and Raman scattering studies of the lattice and methyl-group dynamics in solid p-xylene. Mol. Cryst. Liquid Cryst. Sci. Tech. Section A. Mol. Cryst. Liquid Cryst. 1995, 268, $1-20$.

(13) Prager, M.; Grimm, H.; Natkaniec, I. Rotational tunneling of methyl groups in low temperature phases of mesitylene: potentials and structural implications. Phys. Chem. Chem. Phys. 2005, 7, 25872593.

(14) Neumann, M. A.; Johnson, M. R.; Radaelli, P. G.; Trommsdorff, H. P.; Parker, S. F. Methyl dynamics in durene: a crystallographic, spectroscopic and molecular mechanics investigation. J. Chem. Phys. 1999, 110, 516-527.

(15) Mudge, M.; Ng, B. K.; Onie, M.; Mole, R. A.; Rule, K. C.; Stampfl, A. P. J.; Stride, J. A. What difference does a methyl group make: pentamethylbenzene? ChemPhysChem 2014, 15, 3776-3781.

(16) Stride, J. A.; Adams, J. M.; Johnson, M. R. Lattice modes of hexamethylbenzene studied by inelastic neutron scattering. Chem. Phys. 2005, 317, 143-152.

(17) Ibberson, R. M.; David, W. I. F.; Prager, M. Accurate determination of hydrogen atom positions in $\alpha$-toluene by neutron powder diffraction. J. Chem. Soc., Chem. Commun. 1992, 19, 14381439.

(18) Ibberson, R. M.; Morrison, C.; Prager, M. Neutron powder and $\mathrm{ab}$ initio structure of ortho-xylene: the influence of crystal packing on phenyl ring geometry at $2 \mathrm{~K}$. Chem. Commun. 2000, 539-540.

(19) Ibberson, R. M.; David, W. I. F.; Parsons, S.; Prager, M.; Shankland, K. The crystal structures of m-xylene and p-xylene, $\mathrm{C}_{8} \mathrm{D}_{10}$, at $4.5 \mathrm{~K}$. J. Mol. Struct. 2000, 524, 121-128.

(20) Ibberson, R. M.; Parsons, S.; Natkaniec, I.; HoldernaNatkaniec, K. Structure determination and phase transition behaviour of mesitylene. Z. Kristallogr. Suppl. 2007, 2007, 575-580.

(21) Stride, J. A. Determination of the low-temperature structure of hexamethylbenzene. Acta Crystallogr., Sect. B: Struct. Sci. 2005, 61, 200-206.

(22) Karl, N.; Heym, H.; Stezowski, J. J. Structure, phase diagram and fluorescence spectra of 2,3-dimethylnaphthalene (anthracene) mixed crystals. Mol. Cryst. Liq. Cryst. 1985, 131, 163-191.

(23) Mabied, A. F.; Müller, M.; Dinnebier, R. E.; Nozawa, S.; Hoshino, M.; Tomita, A.; Sato, T.; Adachi, S.-I. A time-resolved powder diffraction study of in-situ photodimerization kinetics of 9methylanthracene using a CCD area detector and parametric Rietveld refinement,. Acta Crystallogr., Sect. B: Struct. Sci. 2012, 68, 424-430.

(24) Marciniak, B. Redetermination of 9,10-dimethyl-anthracene. Acta Crystallogr. E 2007, 63, 3183.

(25) Benda, C.; Klein, W.; Fässler, T. F. Crystal structure of 1,2,3,4,5-pentamethyl-1,3-cyclopentadiene, $\mathrm{C}_{10} \mathrm{H}_{16}$. Z. Kristallogr. N. Cryst. Struct. 2017, 232, 511-512.

(26) Scott, A. P.; Radom, L. Harmonic vibrational frequencies: an evaluation of Hartree-Fock, Møller-Plesset, quadratic configuration interaction, density functional theory, and semiempirical scale factors. J. Phys. Chem. 1996, 100, 15502-16513.
(27) Qu, C.; Bowman, J. M. Quantum approaches to vibrational dynamics and spectroscopy: is ease of interpretation sacrificed as rigor increases? Phys. Chem. Chem. Phys. 2019, 21, 3397-3413.

(28) Puzzarini, C.; Bloino, J.; Tasinato, N.; Barone, V. Accuracy and interpretability: the devil and the holy grail. New routes across old boundaries in computational spectroscopy. Chem. Rev. 2019, 119, $8131-8191$

(29) Drużbicki, K.; Mikuli, E.; Pałka, N.; Zalewski, S.; OssowskaChruściel, M. D. Polymorphism of resorcinol explored by complementary vibrational spectroscopy (FT-RS, THz-TDS, INS) and first-principles solid-state computations (plane-wave DFT). J. Phys. Chem. B 2015, 119, 1681-1695.

(30) Parker, S. F.; Refson, K.; Williams, K. P. J.; Braden, D. A.; Hudson, B. S.; Yvon, K. Spectroscopic and ab initio characterisation of the $\left(\mathrm{ReH}_{9}\right)^{2-}$ ion. Inorg. Chem. 2006, 45, 10951-10957.

(31) Parker, S. F.; Bennington, S. M.; Taylor, J. W.; Herman, H.; Silverwood, I.; Albers, P.; Refson, K. Complete assignment of the vibrational modes of $\mathrm{C}_{60}$ by inelastic neutron scattering spectroscopy and periodic-DFT. Phys. Chem. Chem. Phys. 2011, 13, 7789-7804.

(32) Gibson, E. K.; Callison, J.; Winfield, J. M.; Sutherland, A.; Carr, R. H.; Eaglesham, A.; Parker, S. F.; Lennon, D. Spectroscopic characterisation of model compounds, reactants and byproducts connected with an isocyanate production chain”. Ind. Eng. Chem. Res. 2018, 57, 7355-7362.

(33) Parker, S. F.; Zhong, L. Vibrational spectroscopy of metal methanesulfonates: $\mathrm{M}=\mathrm{Na}, \mathrm{Cs}, \mathrm{Cu}, \mathrm{Ag}, \mathrm{Cd}$. $R$. Soc. Open Sci. 2018, 5, 171574 .

(34) Marciniak, J.; Bąkowicz, J.; Dobrowolski, M. A.; Dziubek, K. F.; Kaźmierczak, M.; Paliwoda, D.; Rajewski, K. W.; Sobczak, S.; Stachowicz, M.; Katrusiak, A. Most frequent organic interactions compressed in toluene. Cryst. Growth Des. 2016, 16, 1435-1441.

(35) Breen, P. J.; Warren, J. A.; Bernstein, E. R.; Seeman, J. I. A study of nonrigid aromatic molecules by supersonic molecular jet spectroscopy. I. Toluene and the xylenes. J. Chem. Phys. 1987, 87, $1917-1926$

(36) Gardner, A. M.; Green, A. M.; Tamé-Reyes, V. M.; Wilton, V. H. K.; Wright, T. G. Vibrations of the low energy states of toluene $\left(\tilde{\mathrm{X}}^{1} \mathrm{~A}_{1}\right.$ and $\left.\tilde{\mathrm{A}}^{1} \mathrm{~B}_{2}\right)$ and the toluene cation $\left(\tilde{\mathrm{X}}^{2} \mathrm{~B}_{1}\right)$. J. Chem. Phys. 2013, $138,134303$.

(37) Gardner, A. M.; Green, A. M.; Tamé-Reyes, V. M.; Reid, K. L.; Davies, J. A.; Parkes, V. H. K.; Wright, T. G. The $700-1500 \mathrm{~cm}^{-1}$ region of the $S_{1}\left(\tilde{\mathrm{A}}^{1} \mathrm{~B}_{2}\right)$ state of toluene studied with resonance enhanced multiphoton ionization (REMPI), zero-kinetic-energy (ZEKE) spectroscopy, and time-resolved slow-electron velocity-map imaging (tr-SEVI) spectroscopy,. J. Chem. Phys. 2014, 140, 114308.

(38) Gascooke, J. R.; Virgo, E. A.; Lawrance, W. D. Direct observation of methyl rotor and vib-rotor states of $S_{0}$ toluene: $A$ revised torsional barrier due to torsion-vibration coupling. J. Chem. Phys. 2015, 142, 024315.

(39) Kanesaka, I.; Naka, H.; Kawai, K. The methyl torsion in toluene $\left(\mathrm{h}_{8}\right.$ and $\left.\mathrm{d}_{8}\right)$ and nitromethane $\left(\mathrm{h}_{3}\right.$ and $\left.\mathrm{d}_{3}\right)$ in the polycrystalline state, J. Chem. Phys. 1979, 70, 5773-5777.

(40) Müller-Warmuth, W.; Schüler, R.; Prager, M.; Kollmar, A. A nuclear relaxation and neutron scattering study of the rotational states of methyl groups in solids with low hindering barriers. J. Magn. Reson. 1979, 34, 83-95.

(41) Cavagnat, D.; Lascombe, J.; Lassegues, J. C.; Horsewill, A. J.; Heidemann, A.; Suck, J. B. Neutron and Raman scattering studies of the methyl dynamics in solid toluene and nitromethane. J. Phys. 1984, 45, 97-105.

(42) Natkaniec, V.; Holderna-Natkaniec, K. Structural phase transitions and dynamics of solid mesitylene investigated by diffraction and inelastic incoherent neutron scattering methods. Advanced Cold Moderators ACoM-6, Proceedings of the 6th International Workshop on Advanced Cold Moderators; Forschungszentrum Jülich, 11-13 September 2002, (ed. H. Conrad), Matter and Materials, 2003; Vol. 20, pp 103-111.

(43) Schreier, R.; Kalus, J. Diffuse X-ray scattering by 2,3dimethylnaphthalene. J. Appl. Crystallogr. 1999, 32, 309. 
(44) Kalus, J.; Gerlach, H.; Schleifer, J.; Wörlen, F.; Voss, G.; Godlewska, M.; Natkaniec, I.; Karl, N.; Prager, M. Inelastic incoherent neutron scattering and Raman scattering of 2,3-dimethylnaphthalene. Phys. Status Solidi B 1986, 134, 53-62.

(45) Iball, J.; Low, J. M. The crystal and molecular structure of 9,10dimethylanthracene,. Acta Crystallogr., Sect. B: Struct. Sci. 1974, 30, 2203-2205.

(46) Ibberson, R. M.; Telling, M. T. F.; Parsons, S. Crystal structures and glassy phase transition behavior of cyclohexene. Cryst. Growth Des. 2008, 8, 512-518.

(47) Parker, S. F.; Fernandez-Alonso, F.; Ramirez-Cuesta, A. J.; Tomkinson, J.; Rudic, S.; Pinna, R. S.; Gorini, G.; Fernández Castañon, J. Recent and future developments on TOSCA at ISIS. J. Phys.: Conf. Ser. 2014, 554, 012003.

(48) https://www.isis.stfc.ac.uk/Pages/home.aspx (accessed on Jan 6, 2020).

(49) Frisch, M. J.; Trucks, G. W.; Schlegel, H. B.; Scuseria, G. E.; Robb, M. A.; Cheeseman, J. R.; Scalmani, G.; Barone, V.; Petersson, G. A.; Nakatsuji, H.; Li, X.; Caricato, M.; Marenich, A.; Bloino, J.; Janesko, B. G.; Gomperts, R.; Mennucci, B.; Hratchian, H. P.; Ortiz, J. V.; Izmaylov, A. F.; Sonnenberg, J. L.; Williams-Young, D.; Ding, F.; Lipparini, F.; Egidi, F.; Goings, J.; Peng, B.; Petrone, A.; Henderson, T.; Ranasinghe, D.; Zakrzewski, V. G.; Gao, J.; Rega, N.; Zheng, G.; Liang, W.; Hada, M.; Ehara, M.; Toyota, K.; Fukuda, R.; Hasegawa, J.; Ishida, M.; Nakajima, T.; Honda, Y.; Kitao, O.; Nakai, H.; Vreven, T.; Throssell, K.; Montgomery, J. A., Jr.; Peralta, J. E.; Ogliaro, F.; Bearpark, M.; Heyd, J. J.; Brothers, E.; Kudin, K. N.; Staroverov, V. N.; Keith, T.; Kobayashi, R.; Normand, J.; Raghavachari, K.; Rendell, A.; Burant, J. C.; Iyengar, S. S.; Tomasi, J.; Cossi, M.; Millam, J. M.; Klene, M.; Adamo, C.; Cammi, R.; Ochterski, J. W.; Martin, R. L.; Morokuma, K.; Farkas, O.; Foresman, J. B.; Fox, D. J. Gaussian 09, Revision 9.5; Gaussian, Inc.: Wallingford CT, 2016.

(50) Clark, S. J.; Segall, M. D.; Pickard, C. J.; Hasnip, P. J.; Probert, M. J.; Refson, K.; Payne, M. C. First principles methods using CASTEP. Z. für Kristallogr.-Cryst. Mater. 2005, 220, 567-570.

(51) Perdew, J. P.; Burke, K.; Ernzerhof, M. Generalized gradient approximation made simple. Phys. Rev. Lett. 1996, 77, 3865-3868.

(52) Tkatchenko, A.; Scheffler, M. Accurate molecular Van der Waals interactions from ground-state electron density and free-atom reference data. Phys. Rev. Lett. 2009, 102, 073005.

(53) Refson, K.; Clark, S. J.; Tulip, P. R. Variational density functional perturbation theory for dielectrics and lattice dynamics. Phys. Rev. B: Condens. Matter Mater. Phys. 2006, 73, 155114.

(54) Groom, C. R.; Bruno, I. J.; Lightfoot, M. P.; Ward, S. C. The Cambridge Structural Database. Acta Crystallogr., Sect. B: Struct. Sci. 2016, 72, 171-179.

(55) Ramirez-Cuesta, A. J. aCLIMAX 4.0.1, The new version of the software for analyzing and interpreting INS spectra. Comput. Phys. Commun. 2004, 157, 226.

(56) Dymkowski, K.; Parker, S. F.; Fernandez-Alonso, F.; Mukhopadhyay, S. AbINS: the modern software for INS interpretation. Physica B 2018, 551, 443-448. 